University of Nebraska - Lincoln

DigitalCommons@University of Nebraska - Lincoln

U.S. Environmental Protection Agency Papers

U.S. Environmental Protection Agency

2004

Visual Plumes mixing zone modeling software

Walter E. Frick

U.S.EPA, frick.walter@epa.gov

Follow this and additional works at: https://digitalcommons.unl.edu/usepapapers

Frick, Walter E., "Visual Plumes mixing zone modeling software" (2004). U.S. Environmental Protection Agency Papers. 166.

https://digitalcommons.unl.edu/usepapapers/166

This Article is brought to you for free and open access by the U.S. Environmental Protection Agency at DigitalCommons@University of Nebraska - Lincoln. It has been accepted for inclusion in U.S. Environmental Protection Agency Papers by an authorized administrator of DigitalCommons@University of Nebraska - Lincoln. 


\title{
Visual Plumes mixing zone modeling software ${ }^{\text {ts }}$
}

\author{
Walter E. Frick* \\ Ecosystems Research Division, NERL, ORD, U.S. EPA, 960 College Station Road, Athens, GA 30605, USA
}

Received 11 March 2002; received in revised form 20 May 2003; accepted 8 August 2003

\begin{abstract}
The US Environmental Protection Agency has a history of developing plume models and providing technical assistance. The Visual Plumes model (VP) is a recent addition to the public-domain models available on the EPA Center for Exposure Assessment Modeling (CEAM) web page. The Windows-based VP adapts, modifies, and enhances the earlier DOS-based PLUMES with a new interface, models, and capabilities. VP is a public platform for mixing zone models designed to encourage the continued improvement of plume theory and models by facilitating verification and inter-model comparison. Some examples are presented to illustrate VP's new capabilities. One demonstrates its ability, for reasonably one-dimensional estuaries, to estimate background concentrations due to tidal re-circulation of previously contaminated receiving water. This capability depends on the optional linkage to time-series input files that enables VP to simulate mixing zone and far-field parameters for long periods. Also described are the new bacterial decay models used to estimate depth changes in first-order decay rates based on environmental stressors, including solar insolation, salinity, and temperature. The nascent density phenomenon is briefly described as it is potentially important to Outer Continental Shelf (OCS) oil exploration discharges.
\end{abstract}

(C) 2003 Elsevier Ltd. All rights reserved.

Keywords: Plumes; Outfalls; Density stratification; Bacteria; Dilution; Mathematical models

\section{Introduction}

Public-domain environmental software provides a way for the regulated and the regulatory communities to develop projects in an environmentally sound way and to assess both proposed projects and changes to existing facilities. For designing and assessing wastewater discharges to marine and fresh surface waters, Visual Plumes exemplifies this model. Introduced in September 2001, Visual Plumes, software and guidance, is available through the EPA Center for Exposure Assessment Modeling web page (CEAM, 2001). After installing the program, users are encouraged to obtain

\footnotetext{
ts This document has been reviewed in accordance with the US Environmental Protection Agency's peer and administrative review policies and approved for publication. Mention of trade names or commercial products does not constitute endorsement or recommendation for use.

${ }^{*}$ Tel.: +1-706-355-8319; fax: +1-706-355-8302.

E-mail address: frick.walter@epa.gov (W.E. Frick).
}

the latest version of the executable from the author via email: frick.walter@epa.gov.

Visual Plumes (VP) uses a familiar Windows-based graphical user interface for model execution and output visualization. The user provides the required information describing the discharge through three input windows (represented by simulated file tabs, see Figs. 13). Both standard, primarily SI, and many nonstandard units may be used. Once familiar with the program, single runs are easy to set up, however, for in-depth analyses, Visual Plumes was designed to handle multiple runs. This is achieved by allowing appropriate time-series files to be linked to the project at hand. The user may review and manipulate model output, both text based and graphical, using the graphical interface.

This paper describes some of the major Visual Plumes features, develops a time-series example to demonstrate its advanced capabilities, and offers some opinions on outstanding topics of interest, including problems encountered in the oil industry: re-circulation, nascent density, and paradigmatic scientific issues. 


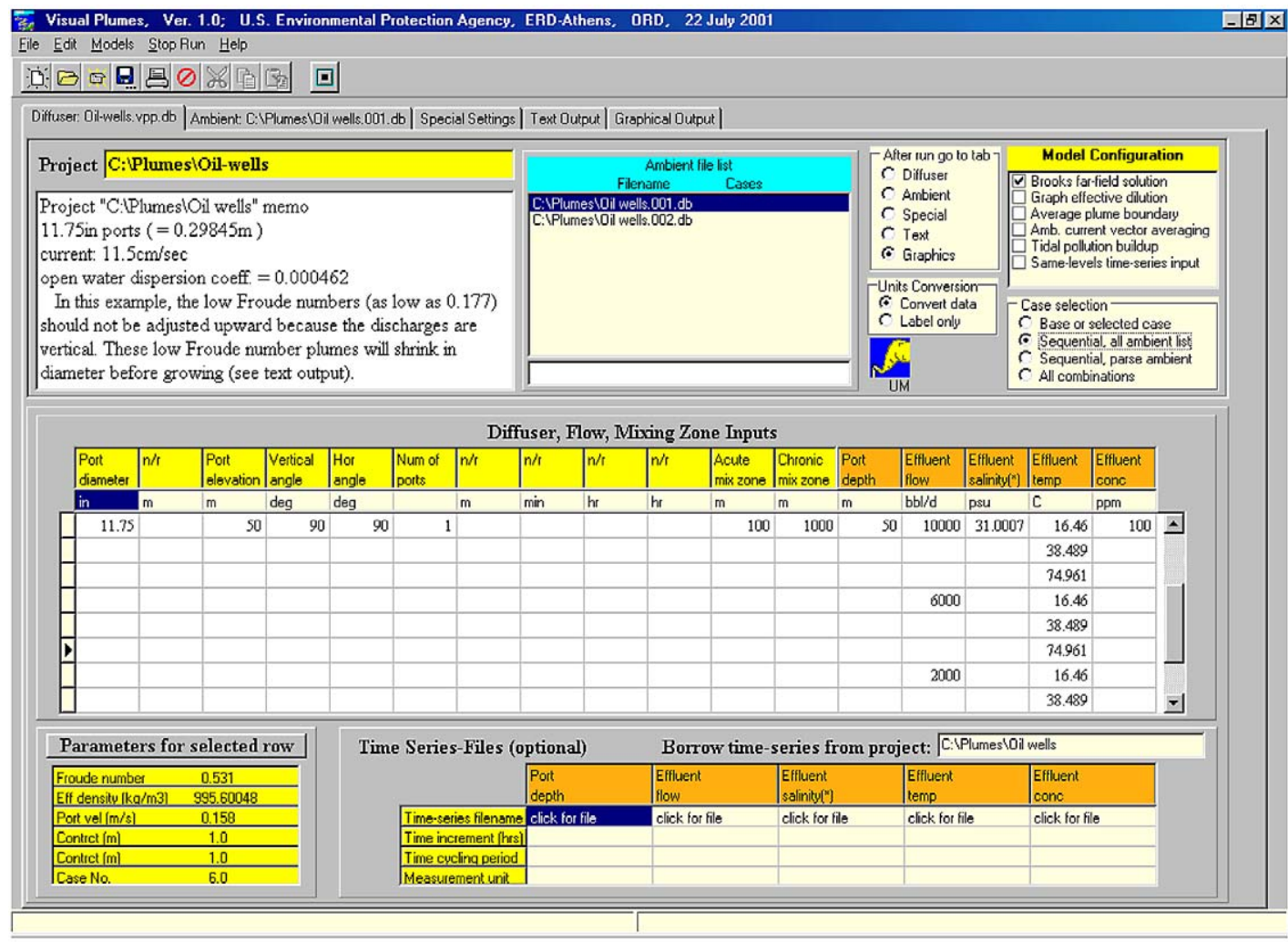

Fig. 1. Visual Plumes' Diffuser tab for the oil well project.

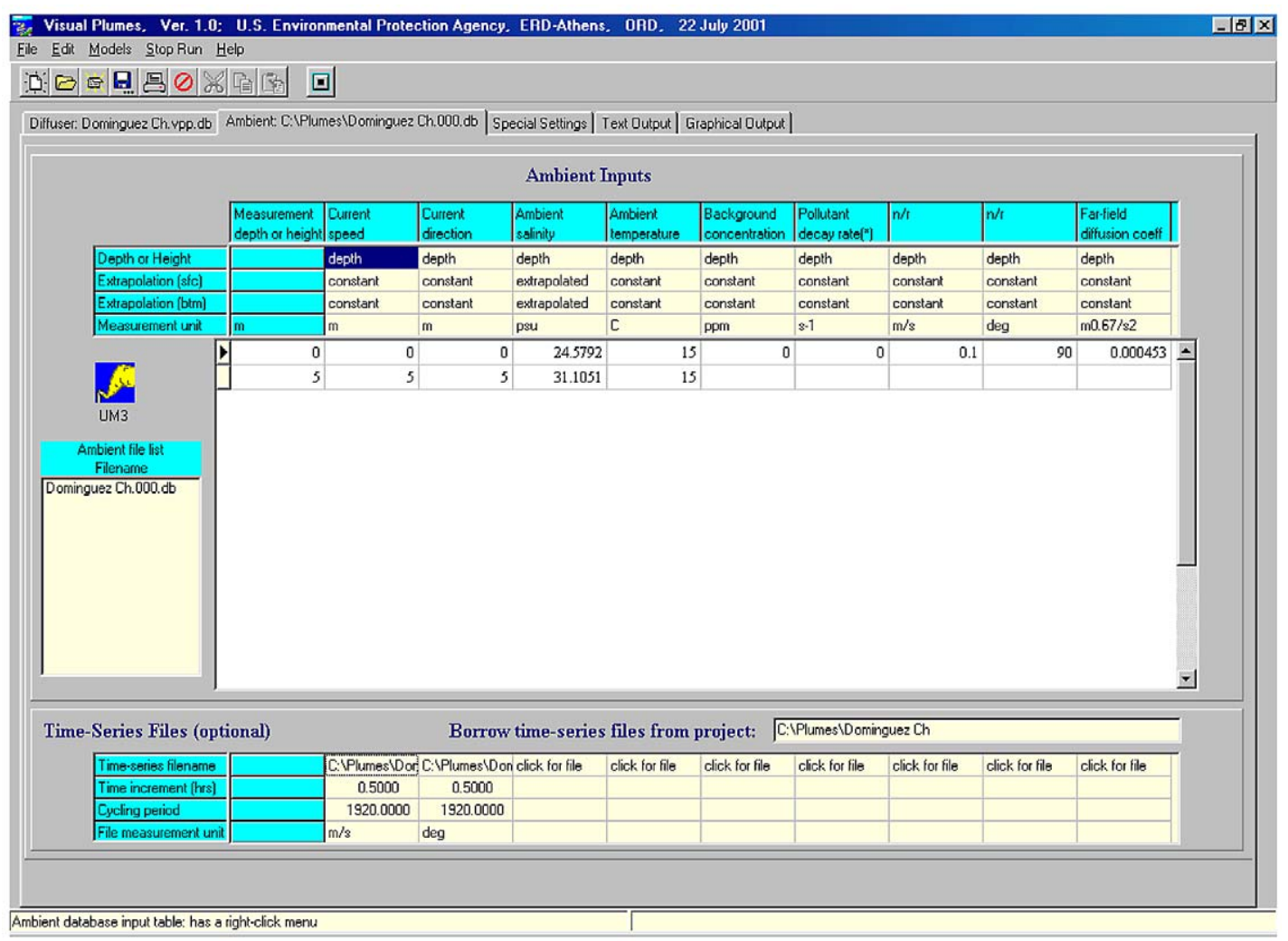

Fig. 2. The Ambient tab for the Dominguez Channel project. 


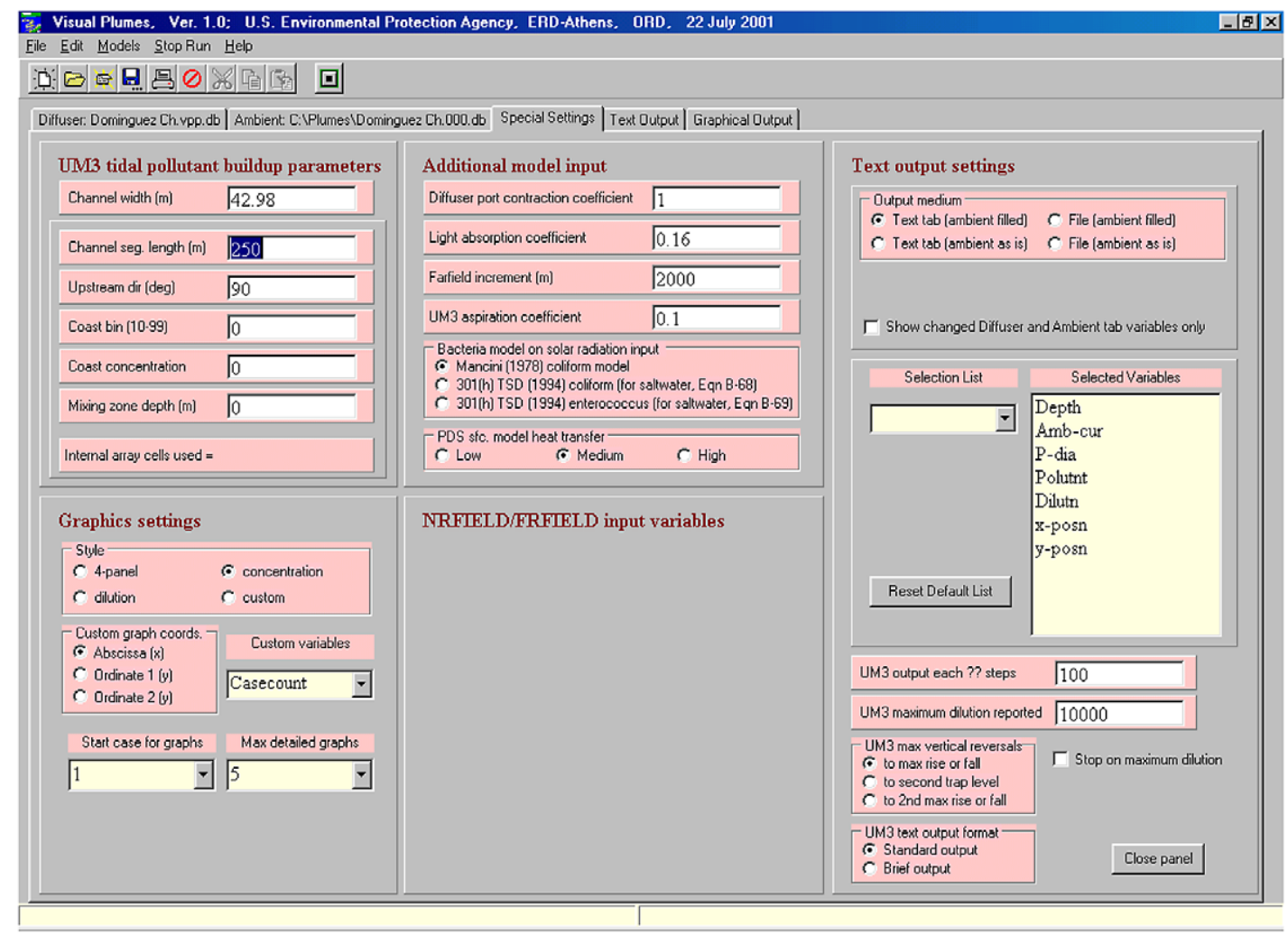

Fig. 3. The Special Settings tab for the Dominguez Channel project.

\section{Visual Plumes}

Visual Plumes (Frick et al., 2002; CEAM, 2001) is a Windows-based program for predicting the dispersive and other physical processes affecting surface water effluents: plumes and jets. Like its DOS-based predecessor, PLUMES (Baumgartner et al., 1994), Visual Plumes (VP) supports multiple initial dilution and farfield models that simulate single and merging submerged plumes in arbitrarily stratified ambient flow. The initial dilution models primarily focus on submerged discharges include DKHW, NRFIELD, and UM3. In addition, there is the PDS surface discharge model. Finally, the Brooks algorithm is used to predict far-field centerline dilution and waste field width. Thus Visual Plumes has a two-fold character, a common graphical interface supporting multiple models that may be selected individually by the user.

The names of the models provide a mix of acronyms, and, historical and descriptive terms. The DKHW model name incorporates author initials and the letter "W" to signify Windows. UM3 is a three-dimensional model based on the earlier UM (Baumgartner et al., 1994) and UMERGE models (Muellenhoff et al., 1985). The RSB model (Baumgartner et al., 1994) is renamed NRFIELD, the new name anticipating future changes.
Visual Plumes provides a convenient way to compare model performance. The support of multiple models represents a commitment to a public modeling platform that will foster scientific competition by encouraging modelers to continue to improve their applications. The ability to run different models consecutively and display the results in graphical form is designed to facilitate model comparison and development. (For 3-D plume depictions, see Lee and Wang, 2002).

Visual Plumes predicts several standard quantities, including dilution, rise, diameter, and other plume variables. But it also has important new capabilities, including multi-stressor bacterial decay models, graphics, time-series input, rudimentary sensitivity analysis, user-specified units, and a tidal background pollutant build-up capability.

VP is backward compatible to support users of DOS PLUMES who wish to revise existing projects or take advantage of previous features, like computing lengthscale, similarity parameters, and related input variables not explicitly supported by VP. DOS PLUMES is one of the "models" that can be run by VP. VP prepares the necessary PLUMES input file and displays the output. It also reads PLUMES input files (files with the $V A R$ extension). 
While it is easy to run single scenarios, VP is designed for multiple cases. In this regard, perhaps no other capability sets VP apart more from earlier programs than its ability to link in ASCII time-series files. This capability provides a way to simulate outfall performance over long periods of time and, thereby, over many environmental scenarios. This is the heart of the pollutant-buildup capability, the ability in onedimensional tidal rivers or estuaries to estimate background pollution due to the source itself. Predictions are displayed graphically to show overall time-series performance.

Technical support experience shows that VP is not particularly intuitive to use. It is easy to complete the interface and run the models but its very flexibility can be confusing. Some of this is due to the fact that some components appear on the interface even when their functions are not utilized. For example, the optional time-series linkage windows are always displayed even when no files are linked. Many specialized input variables are found on the special settings tab. Variable lists for specifying output files show abbreviated names that are not very descriptive. It is not always clear which components possess special capabilities accessed through left or right clicking. The context-sensitive help system is incomplete, and so on. Hopefully future changes will remove or mitigate some of these annoying characteristics. For technical assistance call the author (706/355-8319) or email (frick.walter@epa.gov).

\section{Interface appearance}

The VP Windows-based graphical interface is organized around stacked tabs. The diffuser tab, displayed when VP starts, is devoted to overall program control and diffuser and flow input. The completed diffuser tab for the oil well project further developed below is shown in Fig. 1. Note that VP allows non-SI units to be specified; for example, the flow of 10000 barrels per day shown in the diffuser table, the large block in the middle of the tab, corresponds to $0.0184 \mathrm{~m}^{3} \mathrm{~s}^{-1}$. Nonstandard units may be selected by clicking on the column unit label to reveal a list of available units. Many customized settings are maintained in a project "list" file that bears the project name followed by the "Ist" extension. Blank cells in the table either indicate that the column is not required (labeled $n / r$ ) or, if multiple cases are indicated on successive lines in the table, the value is the same as the one in the previous row. Thus the single additional value on the second line, 38.489C, is all that is required to represent another flow scenario. Note that the flow variables (brown background) starting with Port depth may be time-series variables, however, in this project none of the five variables are linked in as can be established from the empty Timeseries file array at the bottom.

The Model Configuration panel settings control the way VP models, particularly the "native" UM3 model, run and simulation text and graphics are displayed. For example, the ambient file list identifies two associated ambient files. The "Sequential, all ambient list"option on the Case selection panel, instructs VP to do all nine cases when a model is selected to run.

The ambient conditions (for Dominguez Channel project using time-series input) are specified on the ambient tab shown in Fig. 2. In this relatively simple application, all variables have constant values except for current speed and current direction that are read from the linked-in ASCII data files: Dominguez Ch.spd and Dominguez Ch.dir. Evidence of the linkage is reflected by filled cells in the Time-series Files array at the bottom of the tab. The ambient table units for the speed and direction columns are changed to meters and now specify the measurement depths of the input data. Specifying time-series input data at the same depths given in the ambient table allows the direct loading of VP's internal ambient array, bypassing the database functions that are normally necessary to interpret the ambient input table, thereby speeding the simulation of many runs.

The Special Settings tab (for Dominguez Channel project) is given in Fig. 3. Most noteworthy here is the display of the UM3-tidal-pollutant-buildup-parameters cells. Most of the cells on the UM3 tidal pollutant buildup panel are only visible when the Tidal pollutant buildup option is checked on the Model Configuration panel on the diffuser tab.

\section{Time-series input}

One of VP's advanced features is the time-series data input capability. While worst case scenarios have been a mainstay of mixing zone analysis, increasingly users are interested in the continuous performance of outfalls, for example, they may be interested in statistical measures. Also, worst case analysis can be misleading, for example, at fixed distances from the source, like a mixing zone boundary, the highest concentrations are frequently associated with moderate currents (Baumgartner et al., 1994), not with zero currents as commonly believed. The time-series data input capability facilitates such analysis by making multiple VP runs relatively easy to set up and execute.

In the normal VP input mode, the user provides input for a single case or several cases by manually adding the required data to the diffuser and ambient tabs, also setting up and specifying other settings and variables, particularly on the Special Settings tab. Multiple ambient scenarios may be created by using the 
File command, "Save ambient file as" option; this creates a new file that can be modified using the old one as a template.

When linking to time-series data files the diffuser table may only specify a single case and there may be only a single ambient file associated with the project. The time-varying input will be contained in one or several files linked to the project through the optional Time-series files panels on the diffuser and ambient tabs.

Once data are formatted in the prescribed fashion, VP can read the time-series files in place of the input table and provide the corresponding prediction and output. In this way it can analyze many cases in a systematic fashion. The additional time and effort (which depends on the amount of data manipulation required to get the time-series into VP compatible format) may then be recovered by avoiding the numerous ambient input files that would otherwise be required.

\section{Tidal pollutant buildup theory}

Experience shows that one of the greatest pitfalls for users of initial dilution models is to be unaware of the difference between dilution and effective dilution. This is a problem because models have historically reported volume dilution that estimates the relative mixture of ambient and effluent water, not emphasizing the ratio of effluent to plume concentration.

Visual Plumes considers two dilution measures, volume dilution, $S_{a}$, defined as

$S_{a}=\frac{v_{e}+v_{a}}{v_{e}}$

where $v_{e}$ is the initial volume of the plume element (or control volume) and $v_{a}$ is the volume of ambient water incorporated into the plume element in the dilution process, and, effective dilution, $S_{\text {eff }}$ defined as

$S_{e f f}=\frac{c_{e}}{c_{p}}=\frac{1}{\frac{1}{S_{a}}+\frac{c_{a}}{c_{e}}}$

where $c_{e}$ is the effluent pollutant concentration, $c_{p}$ is the plume element concentration at the point of interest, and $c_{a}$ is the ambient concentration (Baumgartner et al., 1994). If $c_{a}$ is zero then $S_{a}=S_{\text {eff }}$, otherwise the effective dilution is typically less than the volume dilution. Effective dilution underscores the fact that a complete mass balance of the dilution process includes the pollutant mass originating in the dilution water. As an example, effluent and ambient concentrations of 100 ppm and $10 \mathrm{ppm}$, respectively, limits effective dilution to 10 , even if volume dilution far exceeds that value. The ambient pollution level puts a lower limit on the concentration that can be achieved by mixing.
If the source contributes to the buildup of ambient concentration in the surface water the effective dilution can degrade over time. It may be the failure in the early 1990s to adopt the effective dilution as the correct measure to protect surface waters that may have contributed to the fact that many NPDES permits subsequently failed to protect water quality. The Total Maximum Daily Loading (TMDL) process now addresses this problem separately.

One way to enable VP to predict effective dilution is to supply ambient concentrations. However, this can be not only tedious, if there are many cases, but ambient measurements are often unavailable. For relatively small, tidal estuaries that are reasonably one-dimensional, VP has a simple way for estimating the buildup of background pollution due to the presence of the source itself. The approach is fairly simple, ignoring the influence of most of the channel details, like morphology and dispersion, on the distribution of pollutants. The approach is used in conjunction with the time-series capability. Necessary data includes the cross-sectional area of the channel at the point of discharge and the water velocity in the channel as a function of time. The manual should be consulted for additional details.

The approach is mass conservative, however, an important underlying assumption is that no redistribution of carrier water from the source is necessary. In other words, all volume contributed by the source is maintained in the fetch element to which it was discharged whenever the element passes over the point of discharge. This continues until the element ceases to pass over the discharge due to the presence of freshwater flow or until it reaches open water. Thus, unnatural water elevations can be implied by this approach that would not occur if the discharged water were routed by a hydrodynamic model. As a result, comparison between measured and observed concentrations at any given time may be adversely affected. However, considered statistically, over a long period of time the approach is expected to give realistic results. For example, while dispersion is not included, the fact that dispersion has symmetry, transporting pollutant both upstream and downstream, suggests that water flowing into the source region from upstream will reach concentrations comparable to those obtained by ignoring dispersion and allowing polluted water to flow up and down stream with the tides. While a predicted high concentration may not be observed at the stated time, such a measurement is likely if flow conditions continue to follow the same pattern. The predictions will be representative of conditions in general.

This buildup approach is most representative when the source is isolated from other sources, so that "natural" background is easily defined, and when the source is sufficiently far upstream so that a fetch 
element does not reach the mouth of the channel during a single tidal cycle. If the natural background is known as a function of time it would be entered as a time-series file and the tidal buildup algorithm would be turned off.

\section{A tidal channel discharge}

The Dominguez Channel example is based on an actual project. The city of Los Angeles, parts of which are situated on a large, low-lying coastal plain, plans to build a rail system between the harbor and downtown, a distance of about $30 \mathrm{~km}$. Much of the right-of-way would be excavated below the water table, necessitating the removal of large volumes of groundwater during construction. The original plan was to discharge it to Dominguez Channel, requiring the issuance of a National Pollution Discharge Elimination System (NPDES) permit. As an old industrial center, the groundwater is unusually high in heavy metals, raising the possibility that water quality criteria in Dominguez Channel could be exceeded.

The initial mixing zone model runs indicated that water quality criteria would be met, however, these analyses did not consider the potential buildup of background pollution. To estimate it with VP it is necessary to establish the water velocity at the discharge point. Available information on the project included an estimate of dry weather flow into the channel and a plot of maximum tidal current speed in the channel as a function of distance from its mouth. Based on this information a time-series record was synthesized using a cosine function of the appropriate lunar frequency. The first two days of the time-series record representing the sum of the steady freshwater drift and the sinusoidal velocity component is shown in Fig. 4. The Delphi (Inprise Corp. trademark) software, used to develop Visual Plumes, is also useful for editing ASCII files, such as the time-series files, as well as for developing peripheral models and programs. However, commercial tide models may be used to synthesize, and predict, tidal currents.

The effective dilution for the simulation period is shown in Fig. 5. The minimum effective dilution declines steadily over a period of days gradually approaching a value of about 3 . In contrast, the minimum volume dilution is about 25 . The highest dilutions, corresponding to the lowest tides when the receiving water moves into the source region for the first time and is free of pollutant, are offscale. Both the effective dilution and, even more obviously, the concentration graphic (not shown), show that the residence time corresponds to about 500 cases $(250 \mathrm{~h})$, or about ten days. A plot showing volume dilution would show a regular pattern of dilutions ranging from about 25 to 60 , grossly misrepresenting the reality of the situation.

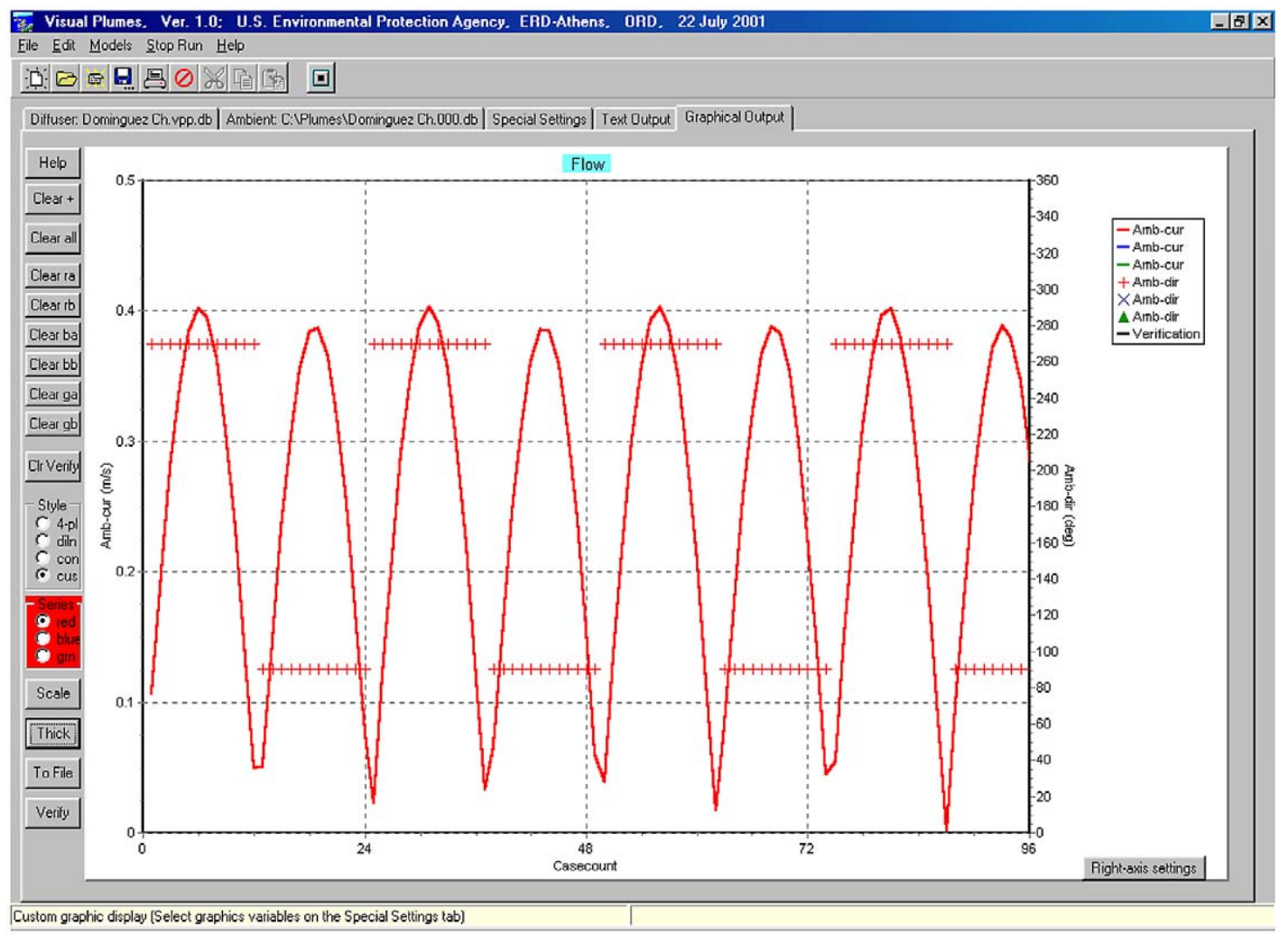

Fig. 4. Part of the synthesized time-series current record used in the Dominguez Channel project. 


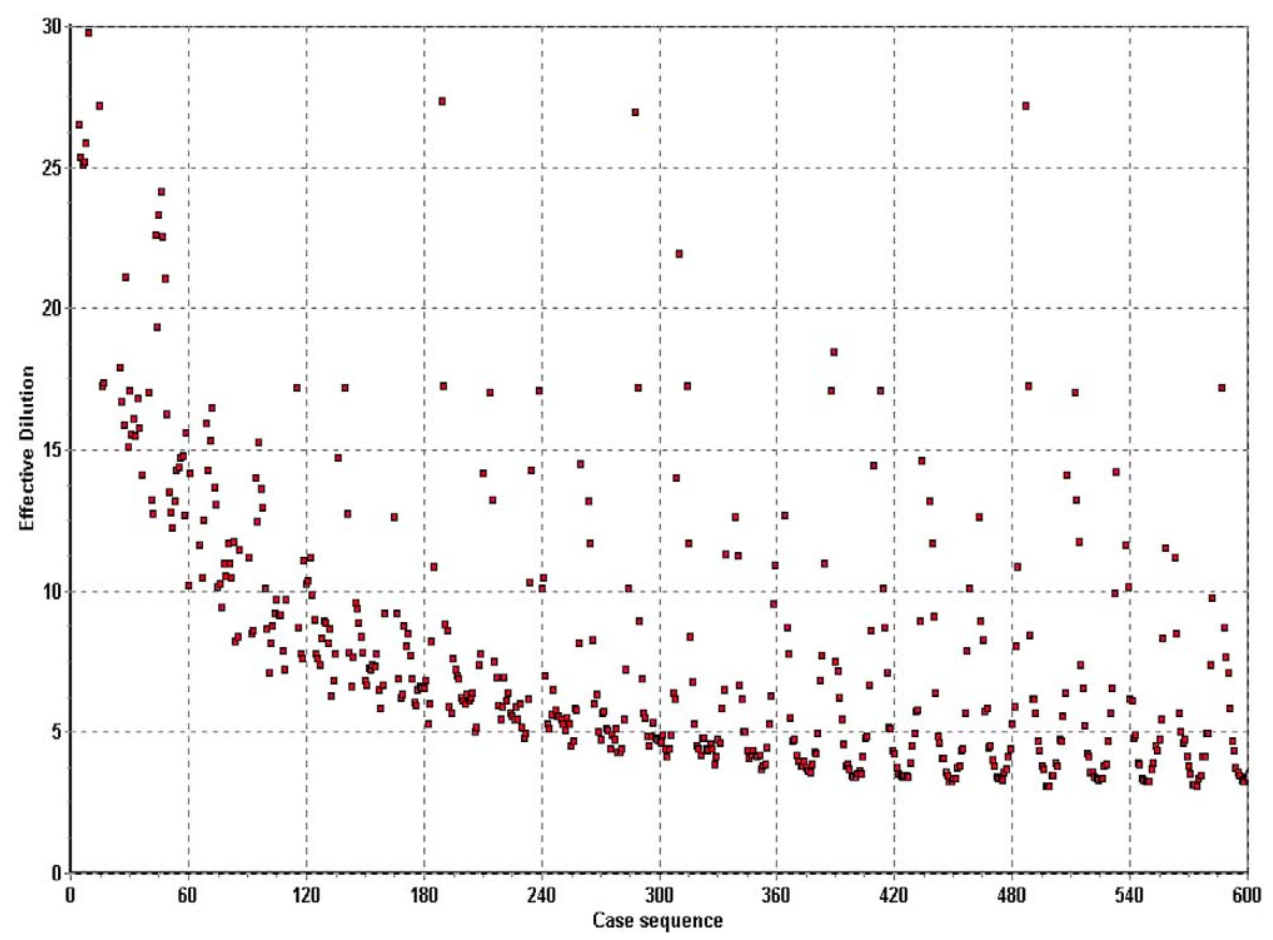

Fig. 5. A decline in effective dilution due to recirculation in a tidal channel, $30 \mathrm{~min}$ interval.

\section{Visual plumes bacterial decay models}

Visual Plumes represents a considerable advance over DOS PLUMES in predicting bacterial mortality. Both use a first order decay equation to estimate concentrations

$C_{t}=C_{o} e^{-\frac{t}{K}}$

where $C_{o}$ is the effluent concentration at time zero, $C_{t}$ is the concentration at a subsequent time, $t$, and $K$ is the mortality rate, often expressed in T-90 h, the length of time required for $90 \%$ of the organisms to die off. However, VP allows $K$ to be calculated when solar insolation and water column turbidity, as well as the standard salinity and temperature inputs, are known.

Like other programs, the VP ambient tab provides a pollutant decay rate column for inputting static values of $K$. But bacteria decay rates vary widely depending on stressor functions, including solar insolation (ultraviolet light), temperature, and salinity. Thus, in tropical waters T-90 times of less than one hour at midday may increase to much higher values at night, potentially making it possible for organisms to survive the journey from the source to bathing beaches.

VP has three models for calculating $K$ from its independent variables, the Mancini (1978) coliform model, and Eqn. B-68 (coliform), and Eqn. B-69 (enterococcus) from the 301(h) Technical Support Document (US EPA, 1984). The Mancini model is the most sophisti- cated of the three

$K=(0.8+0.006 S)\left(1.07^{T-20}\right)+\frac{I_{A}}{k_{e} H}\left(1-e^{-k_{e} H}\right)$

where $S$ is salinity expressed in percent seawater (consistent with the empirical origin of this equation), $T$ is temperature (C), $I_{A}$ is solar insolation (Langleys- $\mathrm{h}^{-1}$ ), $k_{e}$ is the light extinction coefficient $\left(\mathrm{m}^{-1}\right)$, and $H$ is depth (m). The units of $K$ are inverse seconds.

In implementing the Mancini model, it is assumed that $100 \%$ seawater corresponds to 33 psu salinity. Greater salinity affects no change in prediction. However, there are no limits on temperature, elevated temperatures may be outside of the range of experimental values and caution is advised in interpreting the results. Experience with absorption values is very limited at this time, a value of $0.16 \mathrm{~m}^{-1}$ is offered, as shown in Fig. 3.

The TSD coliform equation is implemented as

$K=2.303 e^{2.303(0.0295 T-2.292)}+0.05188 I_{A}$

and the TSD enterococcus equation as

$K=0.02193+0.05188 I_{A}$

Given values, $T=25^{\circ} \mathrm{C}, S=30 \mathrm{psu}, k_{e}=0.16$, and solar intensity of $80 \mathrm{Ly}^{-\mathrm{h}^{-1}}$ (intense sunlight representative of the subtropics) the T-90 time (in $h$ ) for the three models, respectively, is given in Table 1. Surface values are in the range of values found in Grace (1978, p. 129), who goes to some length to discuss the great 
Table 1

Decay times for three models. (T-90 time in h; time in which $90 \%$ of organisms are predicted to die off.)

\begin{tabular}{llll}
\hline Depth & $\begin{array}{l}\text { Mancini model } \\
\text { (coliform) }\end{array}$ & $\begin{array}{l}\text { Eqn. B-68 } \\
\text { (coliform) }\end{array}$ & $\begin{array}{c}\text { Eqn. B-69 } \\
\text { (enterococcus) }\end{array}$ \\
\hline Surface & 0.67 & 0.55 & 0.55 \\
$10 \mathrm{~m}$ & 1.32 & 1.08 & 1.10 \\
$20 \mathrm{~m}$ & 2.13 & 1.76 & 1.81 \\
$50 \mathrm{~m}$ & 4.65 & 3.95 & 4.26 \\
$100 \mathrm{~m}$ & 8.02 & 7.11 & 8.18 \\
\hline
\end{tabular}

uncertainty associated with bacterial decay estimates. The agreement between the Mancini model and Eqns. B-68 and B-69 is quite satisfying, and, it can be said that, at a minimum, VP offers an objective approach to estimated decay rates. The influence of the primary stressor, ultra-violet radiation, is apparent.

When executing, VP uses surface values of solar intensity, in conjunction with the light absorption coefficient on the Special Settings tab, to estimate decay rates at depth. However, inputting surface solar intensity values at all levels on the ambient tab allows computation of the corresponding decay rate through the units conversion facility. The capability was exploited in creating Table 1.

\section{Thermal discharges and oil well brines}

The little-known nascent density effect (Baumgartner et al., 1994) illustrates a potential problem with using linear similarity theory to categorize flow. This phenomenon attributed to the non-linear equation of state for water is appropriately addressed by VP. Thermal discharges and oil well drilling brines often exhibit the phenomenon, due to the range of salinities and temperatures encountered. This unusual behavior depends on the initial properties of the effluent, as well as on the properties of the ambient receiving water. In extreme cases, plumes that are initially buoyant become negatively buoyant and can sink to the bottom instead of trapping or rising to the surface.

The simplest analogy to the nascent density effect in plumes is pond overturning in winter. It is well known that the equation of state for water is non-linear. Unlike most substances that contract continuously upon cooling, fresh water expands before freezing

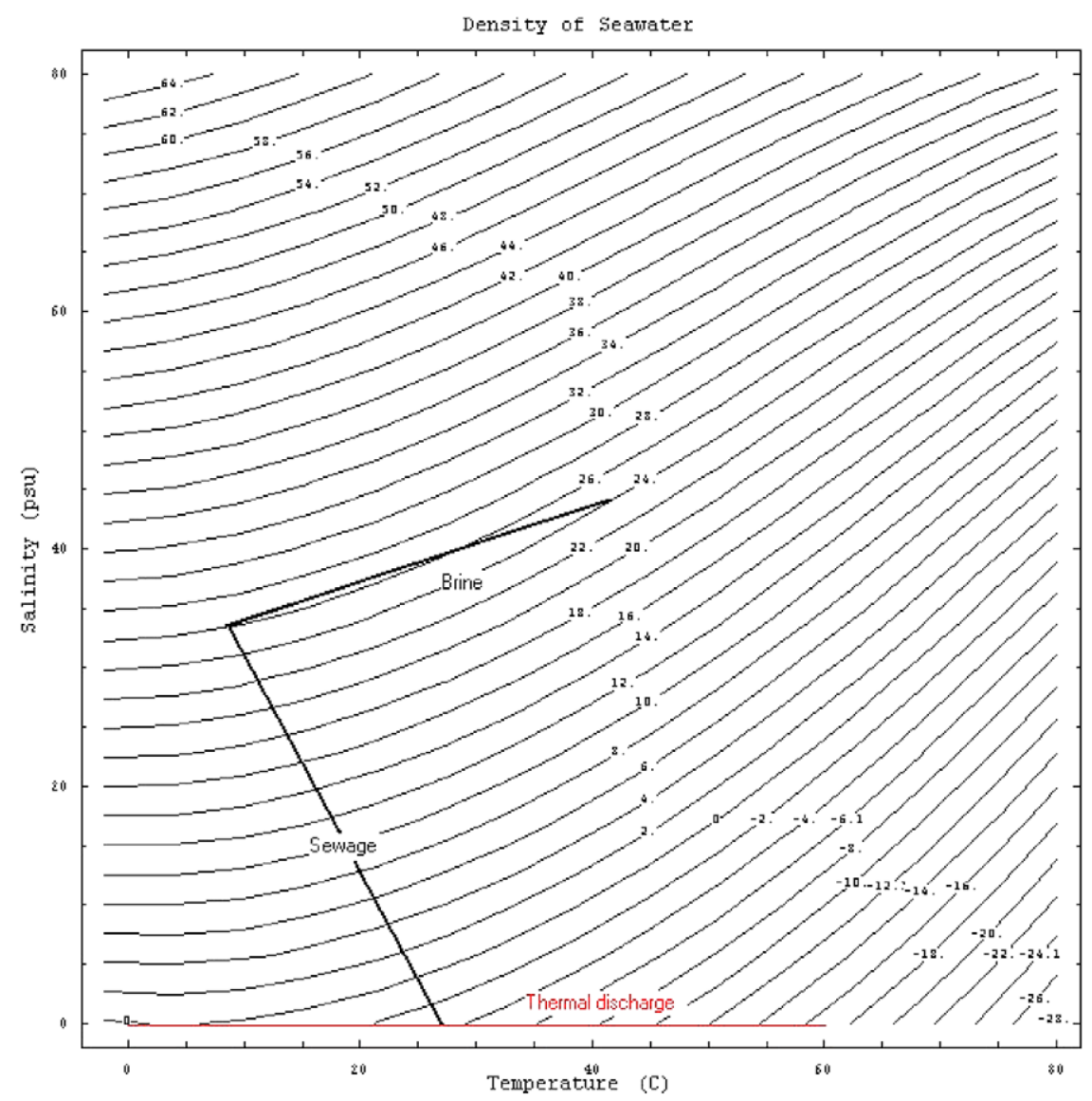

Fig. 6. Density diagram for water as a function of salinity and temperature. Three mixing lines are shown for a warm brine, a sewage effluent, and a thermal discharge. All except the sewage effluent exhibit nascent density effects. 
below about $4{ }^{\circ} \mathrm{C}$. A pond warming slowly in late winter may overturn because, as the surface water warms above $0{ }^{\circ} \mathrm{C}$, it becomes denser than the bottom water with the result that the pond will suddenly "overturn", with denser, but warmer, surface water replacing the colder, but less dense, bottom water.

A similar principle can have profound effects on thermal plumes (Frick and Winiarski, 1978). Consider a fresh water thermal discharge at $60{ }^{\circ} \mathrm{C}$ to a uniformly cooled lake at $0{ }^{\circ} \mathrm{C}$. The temperature in the plume will cool continuously to zero as it mixes in lake water, see Fig. 6. The density will increase correspondingly, and the plume will begin to rise, until the average plume temperature approaches approximately $8{ }^{\circ} \mathrm{C}$. However, below that temperature the plume's density will be greater than the ambient density at $0{ }^{\circ} \mathrm{C}$ and the plume will first decelerate its upward motion, reverse, and finally sink to the bottom.

For a long time it was believed that the nascent density effect was potentially important only in cold, fresh receiving water. Many discharges, like the sewage effluent in Fig. 6, behave in the traditional way. However, some DOS PLUMES users found other conditions in which the nascent density effect is important. Fig. 6 shows the mixing line for a brine, perhaps derived from a water desalination process, discharged to ocean water. It is discharged at about $42{ }^{\circ} \mathrm{C}$ and 43 psu. It is initially and briefly buoyant, but, at below about $28{ }^{\circ} \mathrm{C}$ (dilution about 2:1) it becomes and remains denser than the ambient density. This characteristic of initial buoyance followed by high relative density (a process related to double diffusion) led to this process being called the nascent density effect (Baumgartner et al., 1994).

Fig. 7 shows plume dilutions at maximum rise of eight simulated effluents all possessing the same buoyancy on discharge. The temperature ranges from 0 to $70{ }^{\circ} \mathrm{C}$ in $10{ }^{\circ} \mathrm{C}$ increments but the effluent density is 12 sigma-T units, or $1012 \mathrm{~kg} / \mathrm{m}^{3}$, in all cases, with salinities adjusted accordingly (ranging from 15 to 47.7 $\mathrm{psu}$ ). There are three ambient scenarios (files) of varying density stratification for a total of 24 cases. The discharge-level ambient density is approximately 1015.4 $\mathrm{kg} / \mathrm{m}^{3}$. All eight effluents have the same densimetric Froude number, and, according to similarity theory, should form three identical plumes, one for each ambient scenario. However, as is clear from Fig. 7, maximum-rise dilutions vary widely.

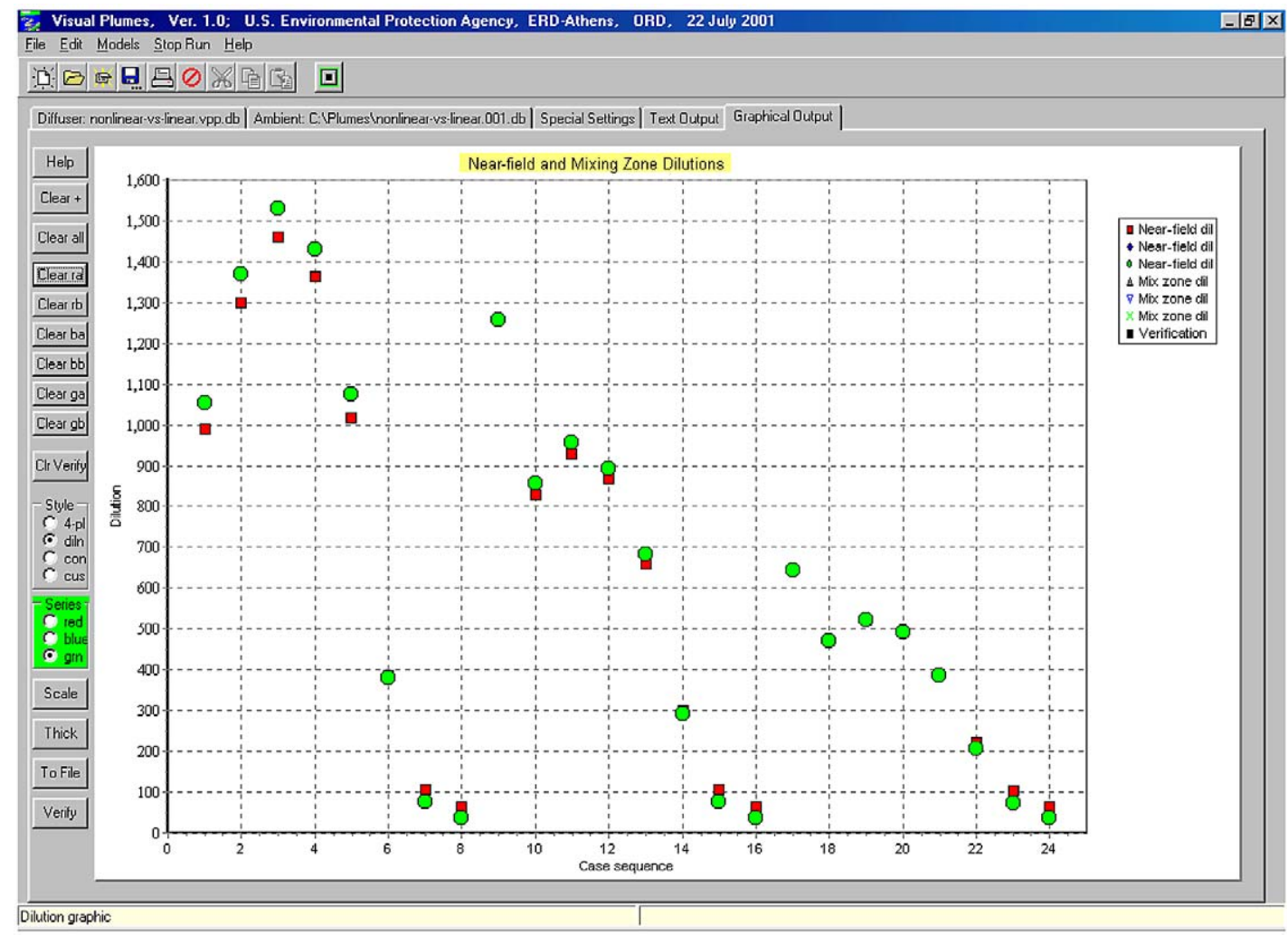

Fig. 7. Variations in predicted maximum rise dilutions for eight effluents described by three densimetric Froude numbers. (Each set of eight simulations corresponds to one of three ambient stratification scenarios.) (Simulations: red squares $=$ DKHW, green $=$ UM3.) 


\section{Conclusion}

Visual Plumes is a Windows-based public domain software available through the Center for Exposure Assessment Modeling web page (CEAM, 2001). It is useful for predicting plume dilution and physical properties, both in the mixing zone and in the far field. Simple scenarios are relatively easy to set up and run, however, its real strength is predicting multiple plume scenarios. In this regard, the time-series file input capability is especially useful.

An important addition to Visual Plumes is its three different bacterial decay models that can predict decay rates from one or more stressor variables, including solar insolation, light absorbance, salinity, and temperature.

Visual Plumes deals well with the nascent density effect. Oil well drilling brine discharges sometimes possess salinities and temperature that give them unusual buoyant properties during the mixing process. Being said to possess nascent density, plumes that are initially buoyant may quickly become negatively buoyant. The reason for this behavior is traced to the non-linearities of the equation of state for water. Thermal discharges often exhibit similar behavior when discharged to cold, fresh water. Similarity theory based on linear models often fails to predict the correct behavior of such discharges.

Visual Plumes provides a common platform for competing models that will make the comparison of models easier and more transparent and deal with consistency outside of the scientific enterprise. This approach can help identify weaknesses in individual models and systemic problems needing to be addressed by the community in general. Consistency, as a regulatory concern, could be addressed by periodically convening experts to outline and refine protocols that, for any given application, would uniquely assign a model to a given problem.

\section{Acknowledgements}

The comments of Drs. Mike Cyterski and John Johnston are gratefully acknowledged.

\section{References}

Baumgartner, D.J., Frick, W.E., Roberts, P.J.W., 1994. Dilution models for effluent discharges, 3rd ed. Pacific Ecosystems Branch, ERL-N, Newport, OR, (EPA/600/R-94/086, 189 pp).

CEAM, 2001. Visual Plumes. USEPA, Center for Exposure Assessment Modeling (CEAM), Athens, Georgia. www.epa.gov/ceampubl/softwwin.htm.

Frick, W.E., Roberts, P.J.W., Davis, L.R., Keyes, J., Baumgartner, D.J., George, K.P., 2002. Dilution models for effluent discharges, 4th ed. (Visual Plumes) USEPA, Athens, Georgia.

Frick, W.E., Winiarski, L.D., 1978. Why Froude number replication does not necessarily ensure modeling similarity. In: Proceedings of the Second Waste Heat Management and Utilization Conference, University of Florida, Coral Gables, FL.

Grace, R.A., 1978. Marine Outfall Systems. Prentice-Hall, Englewood Cliffs, (EPA/600/R-03/025, March 2003. 600 pp).

Lee, J.H.W., Wang, W.P., 2002. Innovative Modeling and Visualization Technology for Environmental Assessment and Education. The Visjet model. http://www.aoe-water.hku.hk/visjet/.

Mancini, J.L., 1978. Numerical estimates of coliform mortality rates under various conditions. J. of the Water Pollution Control Federation $11,2477-2484$.

Muellenhoff, W.P., Soldate, Jr., A.M., Baumgartner, D.J., Schuldt, M.D., Davis, L.R., Frick, W.E., 1985. Initial mixing characteristics of municipal ocean outfall discharges, volume 1. Procedures and Applications (EPA/600/3-85/073a, Nov 1985).

US Environmental Protection Agency, 1994. Amended Section 301(h) Technical Support Document (EPA 842-B-94-007, September 1994). 